\title{
THREE PRINCIPLES TO SUPPORT TEACHER EFFECTIVENESS DURING COVID-19
}

TEACHERS THEMATIC GROUP, WORLD BANK | MAY 2020

$\frac{0}{0}$

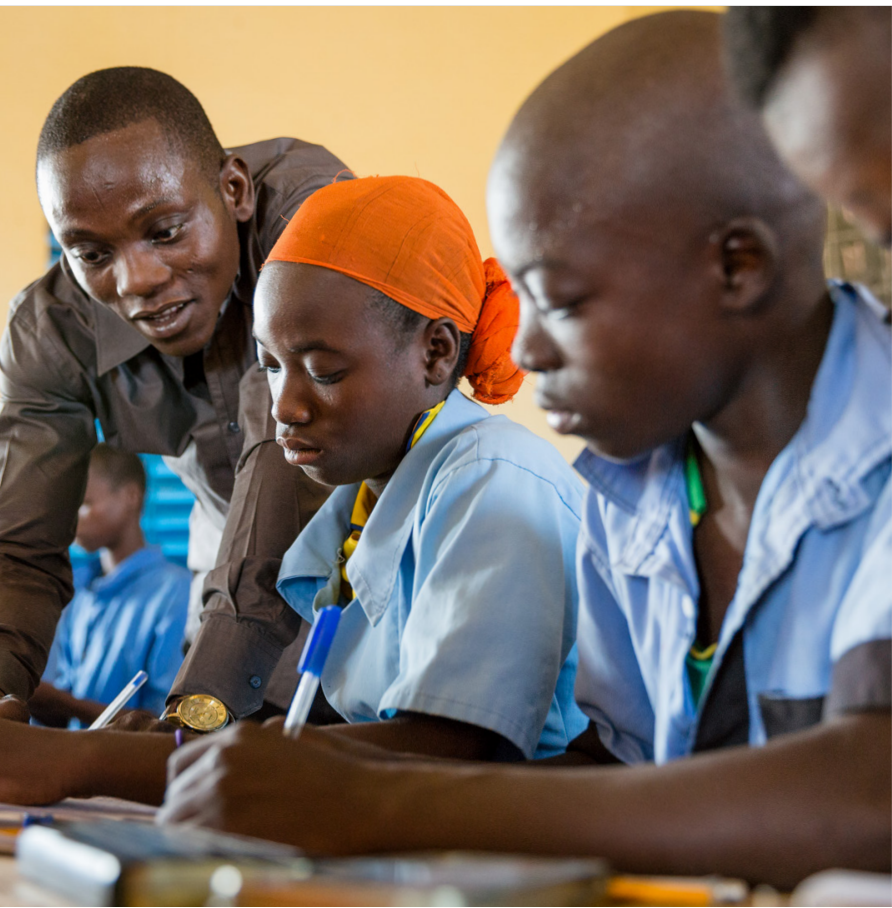

$\mathrm{E}$ ffective teachers are irreplaceable in helping students succeed. They facilitate two-way teaching and learning processes, helping students learn content through real time responses to questions, making learning fun, shaping students' attitudes, exemplifying empathy, modeling teamwork and respect, and building student resilience in several ways. Successful teachers work with school management teams and parents to ensure consistent support for students as they transition through school.

The sudden closure of schools during COVID-19 has left many teachers across several countries uncertain about their role, unable to use technology effectively to communicate and teach, and unprepared for classroom challenges when schools reopen. The pandemic has brought the need to bridge digital divides into sharp focus, with countries and schools adept at using such technologies facing fewer challenges in meeting learning

1 Coping refers to the phase when schools are closed; managing continuity to the phase when they reopen; and improvement

and acceleration to the phase when long-term reform is possible.

goals. There can be little doubt that high-quality education is a social experience, requiring routine human interface. Successful teachers are irreplaceable in this task - and will remain so in the foreseeable future - but they need to be supported in multiple ways to be effective in unpredictable circumstances.

Given the central role teachers play in student learning, this note outlines three key principles to help governments and their development partners in supporting teacher effectiveness during and in the aftermath of COVID-19. It discusses these principles in relation to the three phases of the World Bank's COVID-19 education policy response: coping, managing continuity, and improvement and acceleration. ${ }^{1}$ The three principles are basic and apply regardless of country context.

Principle 1: Support Teacher

Resilience to Ensure Teacher

Effectiveness

Principle 2: Support Teachers

Instructionally to Ensure Teacher

Effectiveness

Principle 3: Support Teachers

Technologically to Ensure Teacher

Effectiveness 


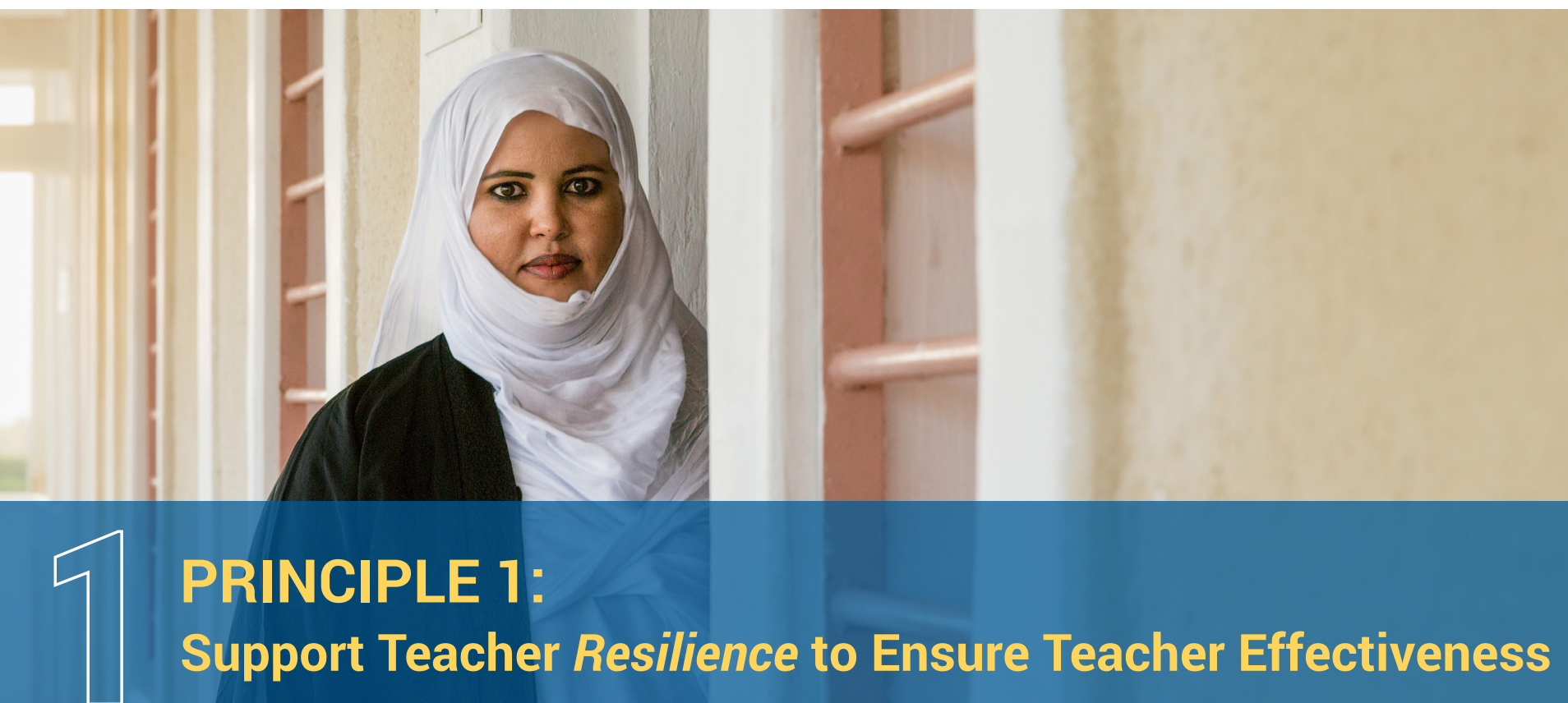

COVID-19 is likely to strain the psychological reserves of all, with everyone facing increased stress due to economic uncertainty, concern for the safety of loved ones, and anxiety about what the future holds. Fostering teacher resilience will be essential for recovery. Given this, three areas require attention during the coping and managing continuity phases for teachers to remain effective:

1. Protect teacher jobs and salaries: As economies struggle to recover and tax revenues fall, teacher positions and salaries will likely be threatened. During the coping and managing continuity phase, countries should protect teacher salaries and jobs so that there is a motivated workforce ready to get students back to speed when schools reopen. Timely payment of teacher salaries is especially important as familiesand potentially extended family members-become dependent on single incomes in the near term, given lay-offs in the public and private sectors.

2. Enhance intrinsic motivation: With schools closed for several months, teachers can play a key role in relaying the government's messages on disease control and mitigation to the community, as many live in the community or liaise with local leaders with effective communication channels. This role will continue once schools reopen. School principals can play a key role in organizing teachers for such roles. High-performing teachers or teacher advisors could offer video and radio lessons on national radio/TV. In Cambodia, for example, the early childhood education subsector produced video clips in response to school closures using teachers evaluated as well-performing during a previous in-service training program. Both are mechanisms to enhance the professional prestige of teachers and teaching, thereby building intrinsic motivation.

3. Limit burnout: As schools reopen, teachers might feel stressed by the prospect of getting infected, the loss of their own skills-given that many may not have participated in routine refresher trainings-as well as the skills of their students. Furthermore, reintegration into schools may be characterized by periods of intermittent closures or multiple shifts to maintain social distancing norms. To cope with stress, teacher and management team culture-especially at the school level - may need to be strengthened as teams can plan addressing challenges together. Regular communication while schools are closed and when they open can help teachers come together. Structured 
peer-support groups are low-cost and can help teachers deal with drastic changes as recent evidence from the Democratic Republic of Congo suggests. Social media can play a key role in building collegial support, as with Facebook/WhatsApp teacher/ school groups in Kenya, South Africa and Pakistan (in process), as would engaging teacher unions/ professional groups to discuss strategies for teacher recovery. Interventions, such as the HealthMinds@ Work-inspired initiative, Education for Wellbeing, in Mexico, can help teachers cultivate important aspects of well-being using simple exercises drawing upon the latest findings in neuroscience, psychology and traditional contemplative perspectives.

As school systems stabilize, and become ready for the improvement and acceleration phase, there will be opportunities to further build the psychological resilience of teachers, ideally led by school management, thereby preparing teachers for future emergencies as well as long-term performance improvement. Opportunities include: (1) specialized counselling units to support teachers' psychosocial needs; while counselling units sometimes exist for students, teachers might also benefit from similar units (for instance, the UAE has a helpdesk for teachers, student and parents); (2) empowering teachers with knowledge and equipment to deal with new emergencies, such as a second wave of COVID infections-as discussed below, this means supporting them with instructional and technological tools; and (3) the aftermath of the emergency provides countries the opportunity to build systems for improving the quality of the teaching force by using incentives to motivate improvement in teacher presence and effectiveness.

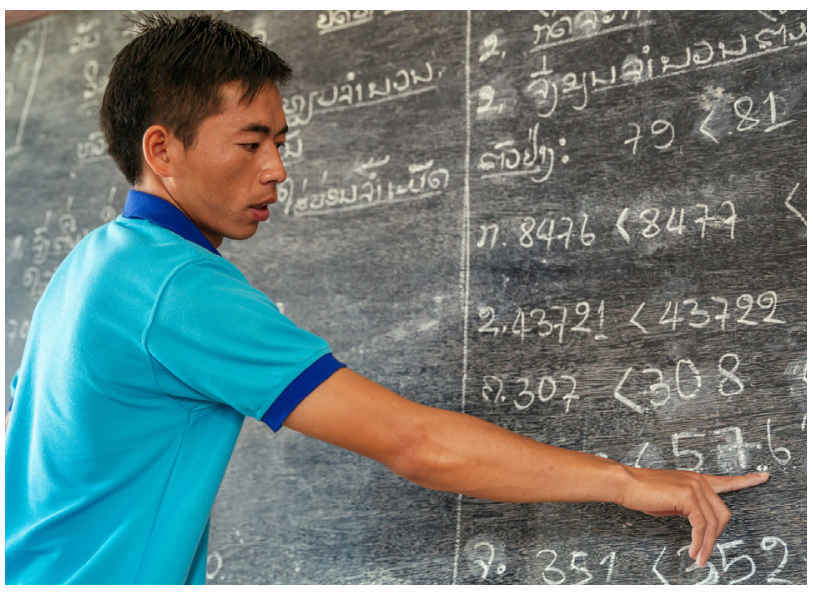

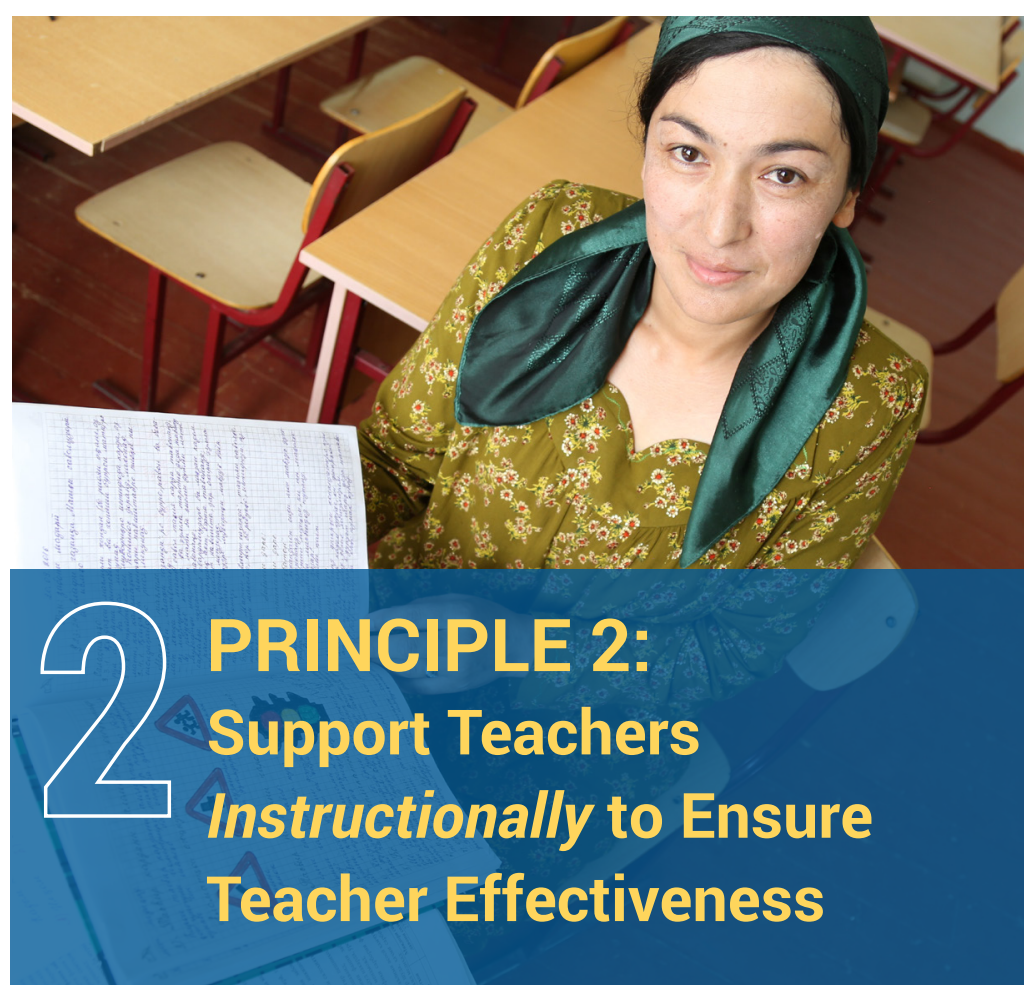

Teachers will return to classrooms where they must manage the potential erosion of their own skills as well as those of their students. In addition to learning loss, there will be loss in the habits of learning, made worse by the overall stress in the aftermath of the pandemic. Teacher professional development strategies should focus on three areas: resilience, recovery and reform. School principals and management will need to support teachers to access multiple trainings; at least one before school starts, followed by regular sessions. Well-resourced systems may even be able to undertake several such trainings during school closure to help teachers reach students and parents effectively. Professional development opportunities during a crisis have the added advantage of addressing burnout by building a sense of community and solidarity among teachers and allowing them to reconnect with colleagues.

Three strategies will be essential in the coping and managing phase to prevent further depletion of learning.

1. Equip teachers to build resilience by ensuring their own and their students' psychosocial wellbeing and hygiene: Teachers will need support as they manage core issues of psychosocial wellbeing and hygiene. 
Even one student can disrupt an entire class, and one coughing child can send waves of panic. Stressreducing exercises can play an important role in helping students and teachers. North Macedonia, for instance, has incorporated stress-reducing exercises for teachers and students in educational television. Once schools reopen, school principals could further help organize and support teacher wellbeing. For this, they should provide clear protocols to deal with new situations such as COVID19. Agreed, documented, and widely understood response mechanisms, which teachers can turn to in times of crises, can relieve teacher stress.

2. Equip teachers to assess students: Once schools reopen, teachers will need to identify what key content and skills-especially foundational onesstudents have either not received or not mastered adequately. For this, teachers will need ready-made assessments or question banks to help them assess students on the core content and skills they should have mastered by this stage. They will need support on assessing students accurately, without generating stress, recording testing information, and using it to help students progress. They will also need to detect warning signs of dropping out and poor mental health. Strong school leadership will be essential in helping teachers carry out these activities.

3. Equip teachers for effective remedial education to expedite recovery: Teachers may need to prioritize students at-risk of dropping out, while ensuring other students don't lose skills. Teachers will need training support to identify at-risk students based on assessments, mitigate factors that might encourage student exit, and bring them to grade level. With

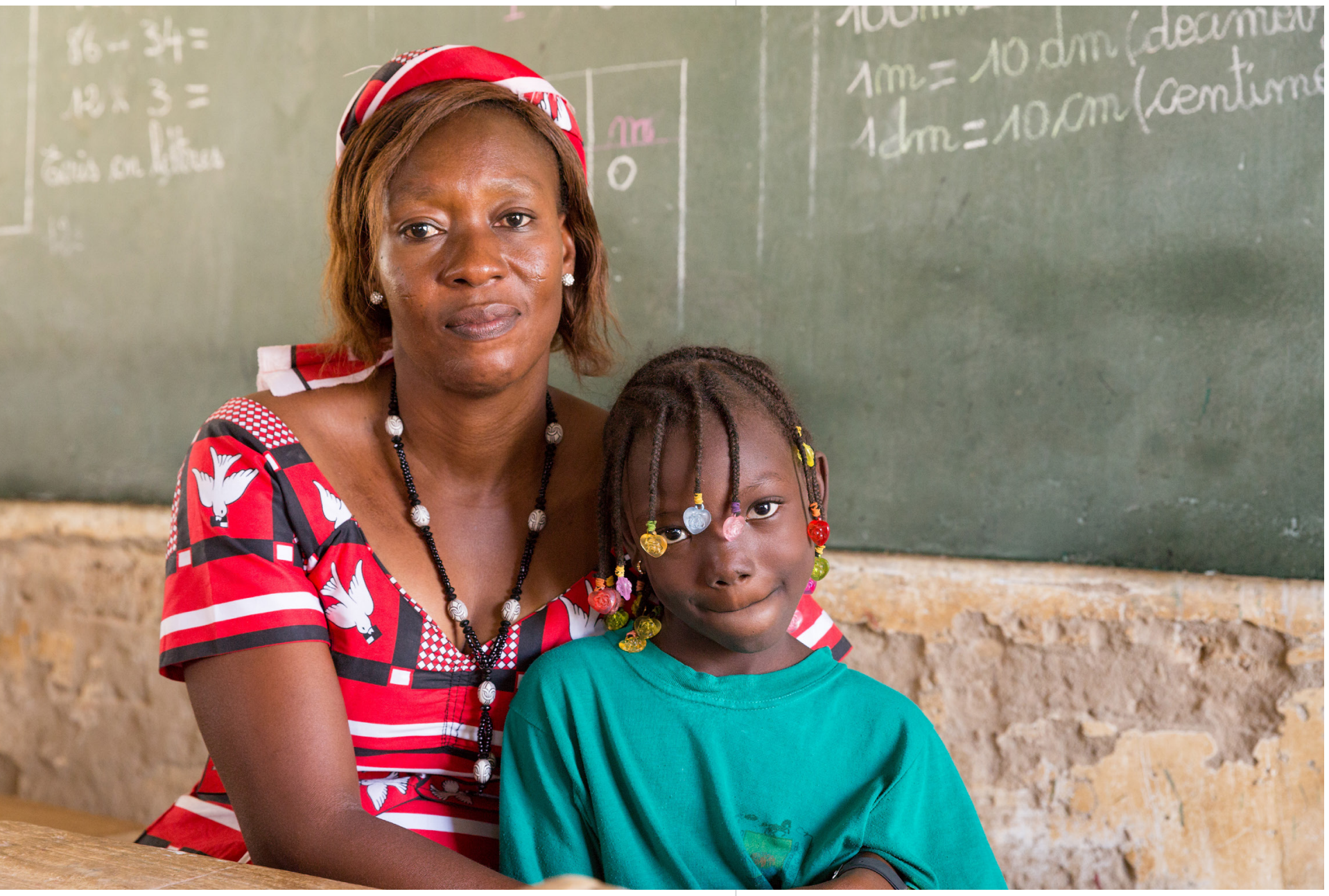


the leadership of school principals and teacher advisors, teachers will need to develop pedagogical strategies to customize their teaching to the level of their students. This may mean becoming proficient at separating students into small ability groups and managing them effectively, such as the approach used in Teaching at the Right Level in several countries, including Botswana and India. Teachers will also need autonomy - and sometimes guidance from school management - in determining how much of the curriculum can be taught effectively when schools open. Where teachers need considerable guidance, structured lesson plans can help with recovery.

As school systems gear up for the improvement and acceleration phase, they should use the opportunity generated by the pandemic to institute important reforms and strengthen teacher professional development to cope with long-term disruptions. Three actions should be prioritized:

1. Emergency-proof the pre-service curriculum: Pre-service curricula should be revised to include elements that help teachers respond to emergencies as well as improve their technology-readiness. After the SARS epidemic in Hong Kong in 2003, schools systematically trained teacher-candidates in the use of technology. Even if teachers cannot communicate with students using virtual classrooms, they should be supported and provided resources to use broadcast to reach students and engage parents; text messages to stay connected with the government and each other; and interactive radio/television and virtual classrooms for their own professional development. Regular and systematic contact between teachers and families is critical in any well-functioning school system; the current pandemic provides the opportunity to build such systems.

2. Reform professional development to be flexible, short, and blended: Professional development should cater more closely to the specific needs of teachers, be available at convenient times for teachers, and blend offline and online mechanisms. In low-technology environments, professional development based on interactive radio or audio can guide teachers

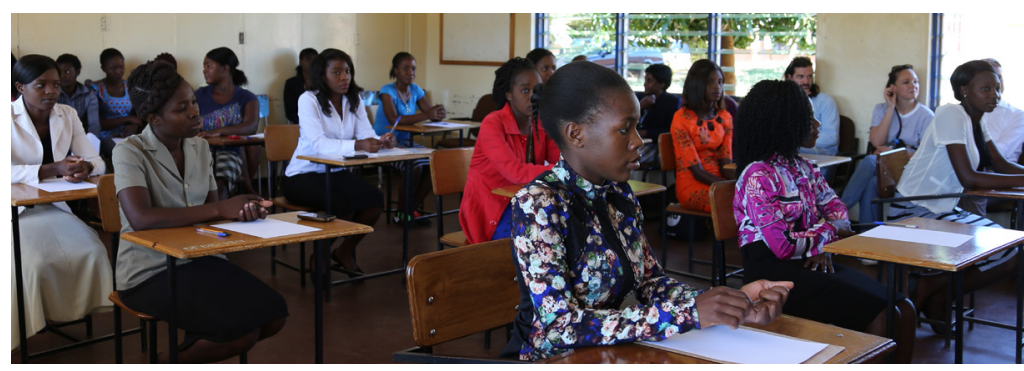

through scripted activities, as with Madagascar's Appui Technique aux Éducateurs et Communautés project. Interactive components such as hours when teachers can call-in, or references to ways teachers can engage real-time through an online link on their phones or through a WhatsApp group to the audio content can increase the effectiveness of training. Television has the added advantage of showing teachers images of teachers and students in action, helping them understand content better as well as desirable and undesirable practice. Such interventions can lay much-needed groundwork for professional development during routine (and non-routine) school closures, improving the effectiveness of future in-person professional development. The pandemic also provides an opportunity to support teachers to improve early grade reading instruction. Across contexts, 400 hours of high-quality, properly sequenced instruction, delivered with appropriate pedagogy can maximize the number of students becoming independent readers by the end of grade 3. Teacher support should revolve around structured lesson plans, and concrete, practical advice for specific improvements in teaching. School principals and management committees will need to play a key role in encouraging teachers to participate in such exercises and apply what they learn in classrooms.

3. Strengthen mechanisms for just-in-time technical support for teachers: Just-in-time technical support may be needed to provide teachers guidance on specific teaching challenges as close to the actual time of teaching. Hotlines and helpdesks, as well as moderated social media platforms, could provide solutions. School principals can play an important role in supporting teachers just-in-time to respond to demands created by new circumstances. 


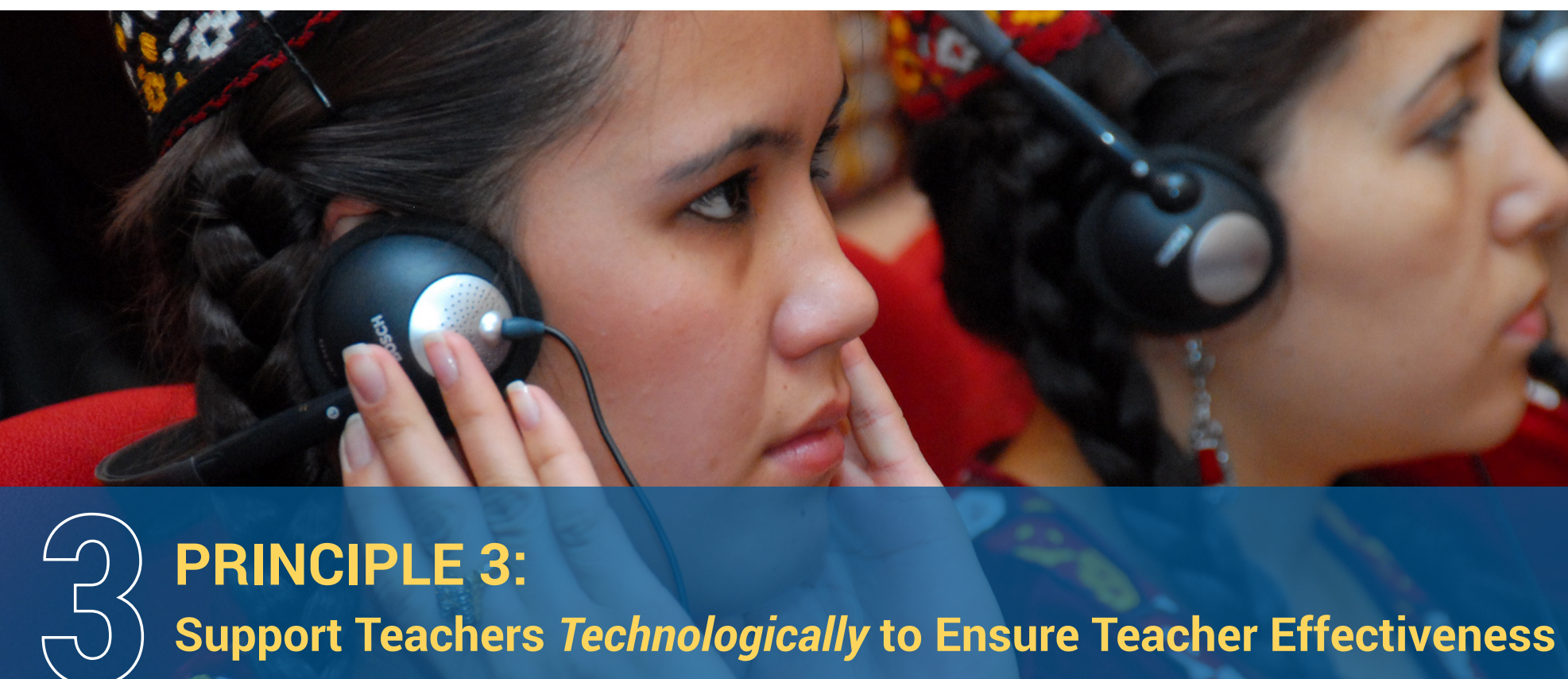

COVID-19 provides an opportunity to require teachers to be technologically skilled as part of their jobs, and not view such skills as purely emergency skills. For teachers to use technology, they must have technology. Even if teachers may not succeed in teaching students using advanced digital technologies in specific countries, they can nevertheless upgrade their own skills and keep communication channels open for both the government and the communities they serve. At a basic level, this requires school systems during the coping phase to:

1. Provide teachers access to broadcast and digital communication channels: All teachers should have easy access to broadcast technologies, such as radio and television, and digital technologies, such as text, phone and email. This requires investment in hardware and connectivity. As schools closed in the Kyrgyz Republic, for instance, teachers were provided with free SIM cards to access educational material online and WhatsApp. In Egypt, the Ministry has set up a platform for student-teacher communication. Orange Liberia is providing free access to online educational content for teachers (and students). In Sao Paulo, Brazil, vulnerable students and teachers have been provided tablets. Tablets will be "repaid" by students through accessing the platform (with progress shared with parents), and by teachers through participating in teacher training

2. Build teacher skills to use broadcast and digital communication channels for teaching: In Lebanon, for instance, the Ministry has been training teachers in the use of Microsoft Teams to record and upload documents and hold virtual classes. Importantly, multiple modes of delivery (offline/online/blended) are more likely to be effective. As such skills are built, flexibility will be important. Not all teachers will approach/adopt technology in the same way. Teachers will need to be supported with diverse strategies for incorporating different technologies. Furthermore, teachers may need to use different channels depending on technology availability. For instance, a suitable multichannel strategy combining lessons broadcasted by TV with SMS or WhatsApp may be more effective in contexts without broad internet access.

3. Encourage teachers frequent use of digital tools for managing communication and learning systems: The more teachers become adept at using digital tools to manage routine communication with the 
government, parents, and students-and undertaking tasks such as assessment or sharing school report cards digitally - the better equipped they will be for future shocks.

As school systems move into the improvement and acceleration phase, they should take the opportunity to require teachers to remain technologically skilled by using technology-enabled systems to reach teachers, meet their HR needs, motivate better attendance and performance, and connect technological tools to learning goals and filling gaps in mastery. School systems should help teachers use technology effectively to remediate gaps in learning and to enhance the ability to cover new material. The new normal will require teachers to be digitally skilled to enrich the teaching-learning experience. Those without such skills risk being ineffective.

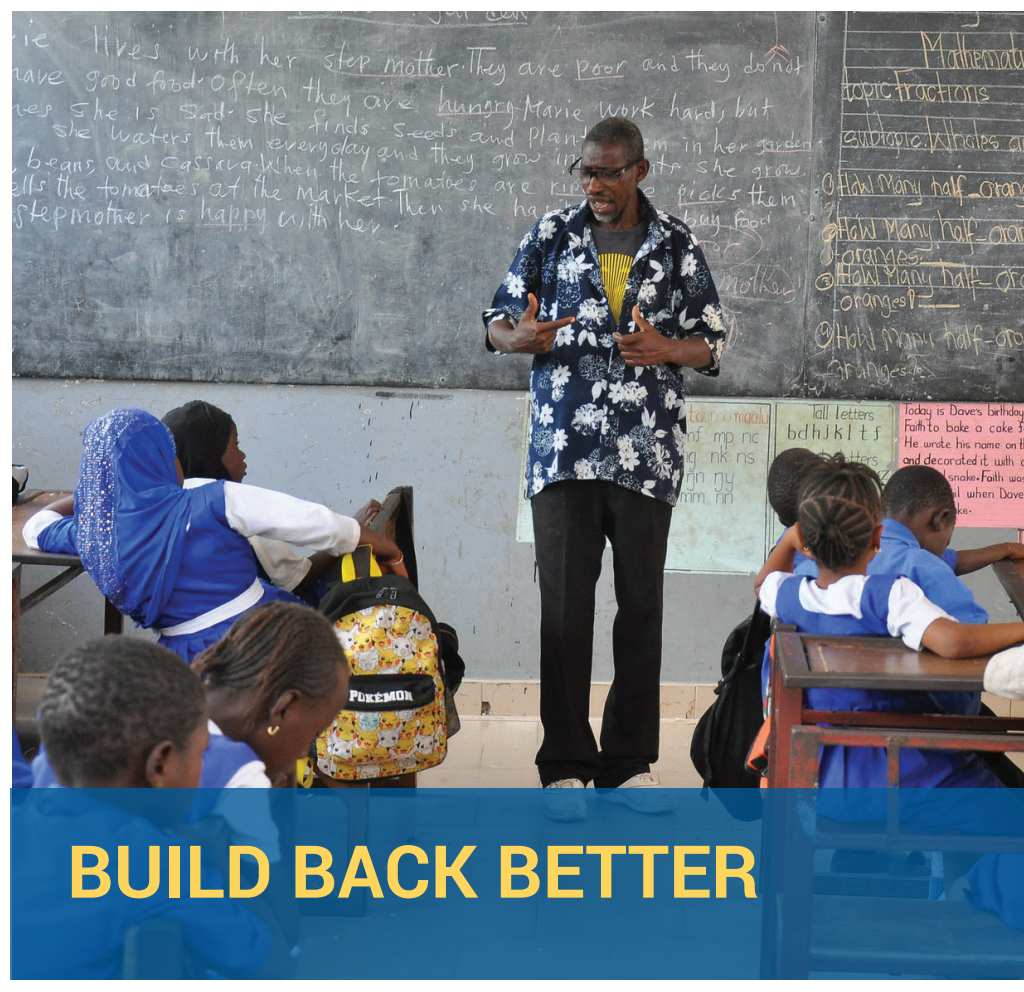

The post-COVID-19 phase will offer many opportunities to "build back better", that is, strengthen the quality of education systems, make them more equitable, and increase their resilience. This note highlights what school systems can do not just in the immediate aftermath of the crisis, but also what can be done to improve in the long run. Even though fiscal constraints will be tight, sharp drops in education financing can have longterm consequences on teacher motivation and effectiveness, and their ability to impact student learning. To build back better, countries will need to devote the financing necessary to solidify improvements. 


\section{References}

Burns, M., 2011. Distance education for teacher training: Modes, models and methods. Washington, DC: Education Development Center.

Cristobal Cobo and Inaki Sanchez Ciarrusta. 2020. Successful Examples of Scaling Up Teaching and Learning in Response to COVID-19. World Bank.

Halsey Rogers, Shwetlena Sabarwal et al. 2020. The COVID-19 Pandemic: Shocks to Education and Policy Responses. The World Bank.

International Task Force on Teachers for Education 2030. Response to the COVID-19 Outbreak Call for Action on Teachers. March 27, 2020.

Jaime Saavedra. 2020. Educational Challenges and Opportunities of the Coronavirus (COVID-19) pandemic. World Bank.

J. Lawrence Aber, Catalina Torrente, Leighann Starkey, Brian Johnston, Edward Seidman, Peter Halpin, Anjuli Shivshanker, NinaWeisenhorn,JeannieAnnan\&SharonWolf(2017)Impacts After One Year of "Healing Classroom" on Children's Reading and Math Skills in DRC: Results From a Cluster Randomized Trial, Journal of Research on Educational Effectiveness, 10:3, 507-529, DOI: 10.1080/19345747.2016.1236160
Michael Trucano. 2020. How Ministries of Education Work with Mobile Operators, Telecom Providers, ISPs and Others to Increase Access to Digital Resources During COVID19 Driven school Closures. World Bank.

Molina, E., Pushparatnam, A., Rimm-Kaufman, S. and Wong, K.K.Y., 2018. Evidence-Based Teaching: Effective Teaching Practices in Primary School Classrooms.

Norwegian Teacher Initiative. Strengthening Multi-Partner Cooperation to Support Teacher Policy and Improve Learning. UNICEF Checklist of Information to be included in Teacher Policy Documents-Draft 16 April 2020.

Robert Fox. "SARS epidemic: Teachers' experiences using ICTs." In Beyond the comfort zone: Proceedings 21st ASCILITE Conference. 2004.

Sharon Zacharia and Alex Twinomugisha. 2020. Educational Television During COVID-19: How to Start and What to Consider. World Bank.

World Bank compilation of country efforts during COVID-19

\section{Acknowledgments}

This brief was prepared by Tara Béteille with Elaine Ding, Ezequiel Molina, Adelle Pushparatnam, and Tracy Wilichowski, under the overall guidance of Omar Arias (Practice Manager, Education Global Practice) and Jaime Saavedra (Global Director, Education Global Practice). The brief benefitted from comments from Juan Baron, Anna Boni, Marguerite Clarke, Cristobal Cobo, Michael Crawford, Bridget Crumpton, David Evans, Toby Linden, Reema Nayar, Harry Patrinos, Louise Ruskin, Alonso Sanchez, and Kumar Vivek.

\section{Photo Credits}

Page 1: "A teacher helps his students in class" by GPE/ Kelley Lynch, license: CC BY-NC-ND 2.0

Page 2: "A teacher outside of her classroom" by GPE/ Kelley Lynch, license: CC BY-NC-ND 2.0

Page 3: "Education in Tajikistan" by GPE/Carine Durand, license: CC BY-NC-ND 2.0

"A teacher at the blackboard" by GPE/ Kelley Lynch, license: CC BY-NC-ND 2.0

Page 4: "A teacher with a new student" by GPE/Kelley Lynch, license: CC BY-NC-ND 2.0

Page 5: "Teacher's College, Zambia, May 2017" by GPE/ Alexandra Humme

Page 6: "Listening to a presentation" by World Bank, license: CC BY-NC-ND 2.0

Page 7: "A teacher and his students in class" by GPE/ Jim Cham, license: CC BY-NC-ND 2.0 